\title{
Pro-oncogene Pokemon promotes breast cancer progression by upregulating survivin expression
}

\author{
Xuyu $\mathrm{Zu}^{1}{ }^{1,2}$, Jun $\mathrm{Ma}^{3}$, Hongxia Liu', Feng Liu', Chunyan Tan', Lingling Yu', Jue Wang ${ }^{1}$, Zhenhua Xie ${ }^{1}$, Deliang Cao ${ }^{3}$ and \\ Yuyang Jiang ${ }^{1,4^{*}}$
}

\begin{abstract}
Introduction: Pokemon is an oncogenic transcription factor involved in cell growth, differentiation and oncogenesis, but little is known about its role in human breast cancer. In this study, we aimed to reveal the role of Pokemon in breast cancer progression and patient survival and to understand its underlying mechanisms.

Methods: Tissue microarray analysis of breast cancer tissues from patients with complete clinicopathological data and more than 20 years of follow-up were used to evaluate Pokemon expression and its correlation with the progression and prognosis of the disease. DNA microarray analysis of MCF-7 cells that overexpress Pokemon was used to identify Pokemon target genes. Chromatin immunoprecipitation (ChIP) and site-directed mutagenesis were utilized to determine how Pokemon regulates survivin expression, a target gene.
\end{abstract}

Results: Pokemon was found to be overexpressed in 158 (86.8\%) of 182 breast cancer tissues, and its expression was correlated with tumor size $(P=0.0148)$ and lymph node metastasis $(P=0.0014)$. Pokemon expression led to worse overall $(n=175, P=0.01)$ and disease-related $(n=79, P=0.0134)$ patient survival. DNA microarray analyses revealed that in MCF-7 breast cancer cells, Pokemon regulates the expression of at least 121 genes involved in several signaling and metabolic pathways, including anti-apoptotic survivin. In clinical specimens, Pokemon and survivin expression were highly correlated $(n=49, r=0.6799, P<0.0001)$. ChIP and site-directed mutagenesis indicated that Pokemon induces survivin expression by binding to the GT boxes in its promoter.

Conclusions: Pokemon promotes breast cancer progression by upregulating survivin expression and thus may be a potential target for the treatment of this malignancy.

\section{Introduction}

Pokemon, also referred to as a factor that binds to inducer of shot transcript 1 (FBI) or leukemia/lymphomarelated factor (LRF), is the product of the ZBTB7 gene [1]. Pokemon is a pro-oncogenic protein overexpressed in lung cancer, diffuse large B-cell lymphomas (DLBCLs), non-Hodgkin's lymphoma (NHL), liver cancer, follicular lymphomas and breast cancer [1-4]. In animals, Pokemon was found to induce cell transformation by repressing the tumor suppressor ARF/p53 pathway [1]. In addition, Pokemon is implicated in transactivation of the human immunodeficiency virus (HIV)-1 Tat gene, adipogenesis, osteoclastogenesis and

\footnotetext{
* Correspondence: jiangyy@sz.tsinghua.edu.cn

'Guangdong Provincial Key Laboratory of Chemical Biology, Graduate School at Shenzhen, Tsinghua University, Lishui Road, Shenzhen 518055, People's Republic of China

Full list of author information is available at the end of the article
}

fatty acid synthesis [5-8]. However, the expression and role of Pokemon in human breast cancer remains unclear.

Pokemon functions as a transcription regulator with active roles in cell growth, differentiation and oncogenesis $[2,9,10]$. Pokemon interferes with GC box recognition by $\mathrm{Sp} 1$ via interacting with the zinc finger DNA binding domain, resulting in the repression of ADH5/ FDH transcription [11]. Pokemon also affects the transcription of nuclear factor (NF)- $\kappa \mathrm{B}$-responsive genes by associating with the p65 subunit and inducing its nuclear import and stabilization [12]. The target genes of Pokemon include extracellular matrix collagen types I, II, IX, X and XI; aggrecan; fibronectin; elastin; cartilage oligomeric matrix protein $(C O M P)$; alcohol dehydrogenase $A D H 5 / F D H, A R F$ and $R b$ tumor suppressors; and c-fos and c-myc oncoproteins $[9,11-15]$. In this
C Biomed Central

() 2011 Zu et al.; licensee BioMed Central Ltd. This is an open access article distributed under the terms of the Creative Commons Attribution License (http://creativecommons.org/licenses/by/2.0), which permits unrestricted use, distribution, and reproduction in any medium, provided the original work is properly cited. 
study, we found that in breast cancer cells, Pokemon stimulates survivin expression by binding to its promoter.

Survivin, a member of the inhibitor of apoptosis proteins (IAP) [16], plays an important role in cell apoptosis and mitotic regulation. Survivin is expressed in fetal and cancer cells, but not in normal adult cells. Survivin is highly expressed in breast, colorectal, lung, gastric and bladder cancers, as well as in melanoma, hepatocellular carcinoma and malignant lymphoma, and its expression in these cancers is associated with poor clinical prognosis [17-25]. Much effort has been made to understand the regulatory mechanism of survivin expression. Various studies have shown that survivin expression is regulated by multiple oncogenes, tumor suppressors and growth factors, such as p53, Sp1, Krüppel-like factor 5 (KLF5) and epidermal growth factor receptor (EGFR) [26-30]. In the present study, we found that survivin expression is correlated with Pokemon expression in human breast cancer cells and demonstrated that Pokemon induces its expression by binding to the $\mathrm{GC}$ boxes in its promoter.

\section{Materials and methods}

\section{Tissue microarray and clinical data}

Microarrays of human breast carcinomas were provided by the Yale Cancer Center Critical Technologies group. Two microarrays were used in this study: Yale Tissue Microarray (YTMA) -23, containing 246 breast cancer cases with complete clinical records and more than 30 years of follow-up (Additional file 1), and YTMA-89, consisting of 54 recurrent breast cancer cases. Paraffinembedded, formalin-fixed specimens of breast carcinoma tissue were identified from the archives of the Yale University Department of Pathology as available from 1961 to 1983. Complete treatment information was unavailable for the entire cohort of 246 primary breast cancer cases, but most patients were treated with postsurgical local radiation. None of the node-negative patients were given adjuvant systemic therapy. Among the node-positive patients, approximately $15 \%$ were given chemotherapy primarily consisting of adriamycin, cytoxan and 5-fluorouracil, and some were given tamoxifen (post-1978) [31,32]. Another two adjacent arrays composed of 50 breast cancers with matching normal adjacent tissues were obtained from Cybrdi, Inc. (CC081-07; Cybrdi, Inc., Rockville, MD, USA). Ethical approval for this study was obtained from the human research ethical advisory committee of Tsinghua University.

\section{Cell culture}

The human breast cancer cells MCF-7 and MDA-MB231 (American Type Culture Collection, Manassas, VA, USA) were maintained in Dulbecco's modified Eagle's medium (DMEM) supplemented with 10\% heated fetal bovine serum (FBS), $2 \mathrm{mM}$ glutamine, $100 \mathrm{U} / \mathrm{ml}$ penicillin and $100 \mu \mathrm{g} / \mathrm{ml}$ streptomycin at $37^{\circ} \mathrm{C}$ and $5 \% \mathrm{CO}_{2}$.

\section{Immunohistochemistry}

After dewaxing and hydration, tissue microarray slides were immersed into preheated citric acid buffer $(\mathrm{pH} 6.5)$ at $90^{\circ} \mathrm{C}$ to $95^{\circ} \mathrm{C}$ for 20 minutes with microwaving. After being blocked with $5 \%$ horse serum for 30 minutes, slides were incubated with anti-Pokemon or anti-survivin antibodies (1:50; Abcam, Cambridge, MA, USA) at $4^{\circ} \mathrm{C}$ in a humid box overnight. Thereafter slides were washed three times and then incubated with horseradish peroxidase-conjugated secondary antibody (1:800; Pierce Biotechnology, Rockford, IL, USA) at room temperature for 1 hour. Enhanced 3,3'-diaminobenzidine staining buffer (Pierce Biotechnology) was used to visualize signals. Staining intensity was evaluated blindly by at least one researcher and one pathologist and was scored from 0 to 3 , representing negative and low, intermediate and high staining, respectively.

\section{Plasmid construction}

Pokemon-expressing plasmid was generated by inserting the encoding region into pcDNA3.1 expression vector (Invitrogen, Carlsbad, CA, USA) at the site of the HindIII restriction enzyme. Pokemon primer pairs were 5'CTT AAG CTT GCC ACC ATG GCC GGC GGC GTG G-3' and 5'-GTC AAG CTT TTA GGC GAG TCC GGC TGT GAA GTT AC-3'. Survivin promoter was subcloned into pGL4.10 basic plasmid (Promega, Madison, WI, USA) at the BamHI and EcoRV restriction enzyme sites to drive luciferase expression. The amplification primer pairs were 5'-GTC AGA TCT AGT GAA AAG GAG TTG TTC CTT TCC TCC CTC-3' and 5'GTC AAG CTT GCC GCC GCC GCC ACC TC-3' for a 2,082-bp fragment, 5'-GTC AAG CTT GCC GCC GCC GCC GCC ACC TC-3' and 5'-GTC AGA TCT AAA GAC AGT GGA GGC ACC AGG C-3' for a 1,054-bp fragment, and 5'-GTC AAG CTT GCC GCC GCC GCC ACC TC-3' and 5'-GTC AGA TCT TTG GGA TTA CAG GCA TGC ACC AC-3' for a 441-bp fragment.

\section{Site-directed mutagenesis}

Mutants (pLuc-95 m and pLuc-231 m) of survivin promoter were generated using an in vitro site-directed mutagenesis system (Promega). The GGGTG sequence in the binding site of Pokemon was replaced by AAAAA and confirmed by sequencing.

\section{cDNA microarray analysis}

Human cDNA microarrays covering $22 \mathrm{~kb}$ cDNA spots (CapitalBio, Beijing, China) were used. In brief, total RNA was extracted from MCF-7 cells with ectopic 
Pokemon expression and vector control using the TRIzol reagent (Invitrogen), and fluorescence-labeled cDNA probes were made for hybridization using $30 \mu \mathrm{g}$ of total RNA with an oligo(dT)18 primer and SuperScript II Reverse Transcriptase (Gibco BRL, Carlsbad, CA, USA). Hybridized slides were scanned using a LuxScan 10K-A confocal laser microscopy scanner, and signal intensities for each spot were calculated by subtracting local background using LuxScan 3.0 software (CapitalBio). Three independent replicates were conducted, and the spot with $\geq 2$.0-fold increase or decrease was considered a significant change. Gene expression signaling pathways were analyzed with MAS2.0 software (CapitalBio) [GEO: GSE27442].

\section{Pokemon silencing and Western blot analysis}

Pokemon expression in MDA-MD-231 breast cancer cells was knocked down using chemically synthesized small interfering RNA (siRNA) siRNA\#1 (targeting 426 to 444 bp, sense 5'-GCU GGA CCU UGU AGA UCA Att-3', and antisense 5'-UUG AUC UAC AAG GUC CAG Ctt-3'), siRNA\#2 (targeting 476 to $494 \mathrm{bp}$, sense 5'-AGU ACC UCG AGU UCU UCC Att-3', and antisense 5'-UGG AAG AAC UCG AGG UAC Utt-3') [13] and siRNA\#3 (targeting 624 to 642 bp, sense 5'-GGA GUA CCU CGA GUU CUU Ctt-3', and antisense 5'-GAA GAA CUC GAG GUA CUC Ctt-3'). The siRNA were introduced as described previously [33], and protein knockdown was examined using Western blot analysis [34]. Soluble proteins $(30 \mu \mathrm{g})$ were probed with anti-Pokemon (1:500), anti-survivin, antip14ARF and anti-Bcl-2 antibodies (1:500) (Abcam). Loading variations were normalized against $\beta$-actin, which was identified by anti- $\beta$-actin monoclonal antibody (Sigma, St. Louis, MO, USA).

\section{Transient transfection and luciferase activity assay}

Transient gene delivery was carried out to assess the effect of Pokemon on survivin promoter activity in MDA-MB-231 and MCF-7 cells as described previously $[35,36]$. Briefly, $1 \times 10^{5}$ cells were mixed with survivin promoter constructs and Pokemon expression vector or Pokemon siRNA\#1. At 48 hours after transfection, cell extracts were prepared with $1 \times$ lysis buffer, and a $10-\mu \mathrm{l}$ aliquot of the supernatant was mixed with $50 \mu \mathrm{l}$ of luciferase assay reagent (Promega) and analyzed with a Microplate Luminometer (Beckman Coulter, Fullerton, CA, USA). Luciferase activity was normalized by using a Renilla luciferase internal control.

\section{Chromatin immunoprecipitation assay}

MCF-7 and MDA-MB-231 cells were fixed by the addition of $1 \%$ formaldehyde to the medium for 10 minutes. Formaldehyde was quenched by the addition of $1 \times$ glycine for 5 minutes at room temperature. A chromatin immunoprecipitation (ChIP) assay was performed as described previously [37] with $3 \mu \mathrm{l}$ of immunoprecipitated DNA and primers (forward 5'-GTC AAG CTT GCC GCC GCC GCC ACC TC-3' and reverse 5'-GTC AGA TCT TTG GGA TTA CAG GCA TGC ACC AC3 ) located at -441 to $-418 \mathrm{bp}$ and -17 to $+1 \mathrm{bp}$ of the survivin promoter.

\section{Statistical analysis}

Spearman's rank-correlation coefficients were used to assess the relationship between Pokemon and survivin expression, the Wilcoxon rank-sum test or the KruskalWallis test were utilized with categorical variables and Kaplan-Meier survival curves were produced to examine the relationship between Pokemon expression and mortality. Results were considered statistically significant at $P<0.05$.

\section{Results}

\section{Overexpression of Pokemon in breast cancer is positively} correlated with disease progression

The YTMA-23 tissue microarray, provided by the Yale Cancer Center Critical Technology Group, was evaluated for Pokemon expression. This array consists of 246 breast cancer cases and normal controls, among which 182 malignant tissues were histologically interpretable. The results showed that Pokemon was undetectable in normal breast lobules, but overexpressed in 158 (86.8\%) of 182 cancerous tissues. The level of Pokemon expression was assessed according to the intensity of immunostaining and assigned the score of 0 to 3 (negative to most intensive) (Figure 1A). This YTMA-23 microarray came with complete clinical records and follow-up, and therefore the correlation between Pokemon expression and clinical pathological parameters was analyzed. As summarized in Table 1, Pokemon expression correlated positively with tumor size $(P=0.0148)$ and lymph node metastasis $(P=0.0014)$, but not with patient age, tumor type and nuclear grade. Pokemon was also found to be overexpressed in 28 (80\%) of 35 interpretable recurrent breast tumors in another YTMA-89 microarray.

Tumor size and lymph node metastasis are wellknown prognostic factors for breast cancer, and therefore the effect of Pokemon expression on patient survival was further analyzed using Kaplan-Meier plots. As shown in Figure 1B, Pokemon expression was negatively correlated with overall survival $(n=175, P=0.01)$ and in particular disease-related survival $(n=79, P=$ 0.0134 ) of breast cancer patients, indicating that Pokemon is a negative prognostic indicator.

The estrogen receptor (ER), progesterone receptor (PR) and human epidermal growth factor receptor 2 (HER2) genes are well-established biomarkers and therapeutic targets for breast cancer. The correlation of 


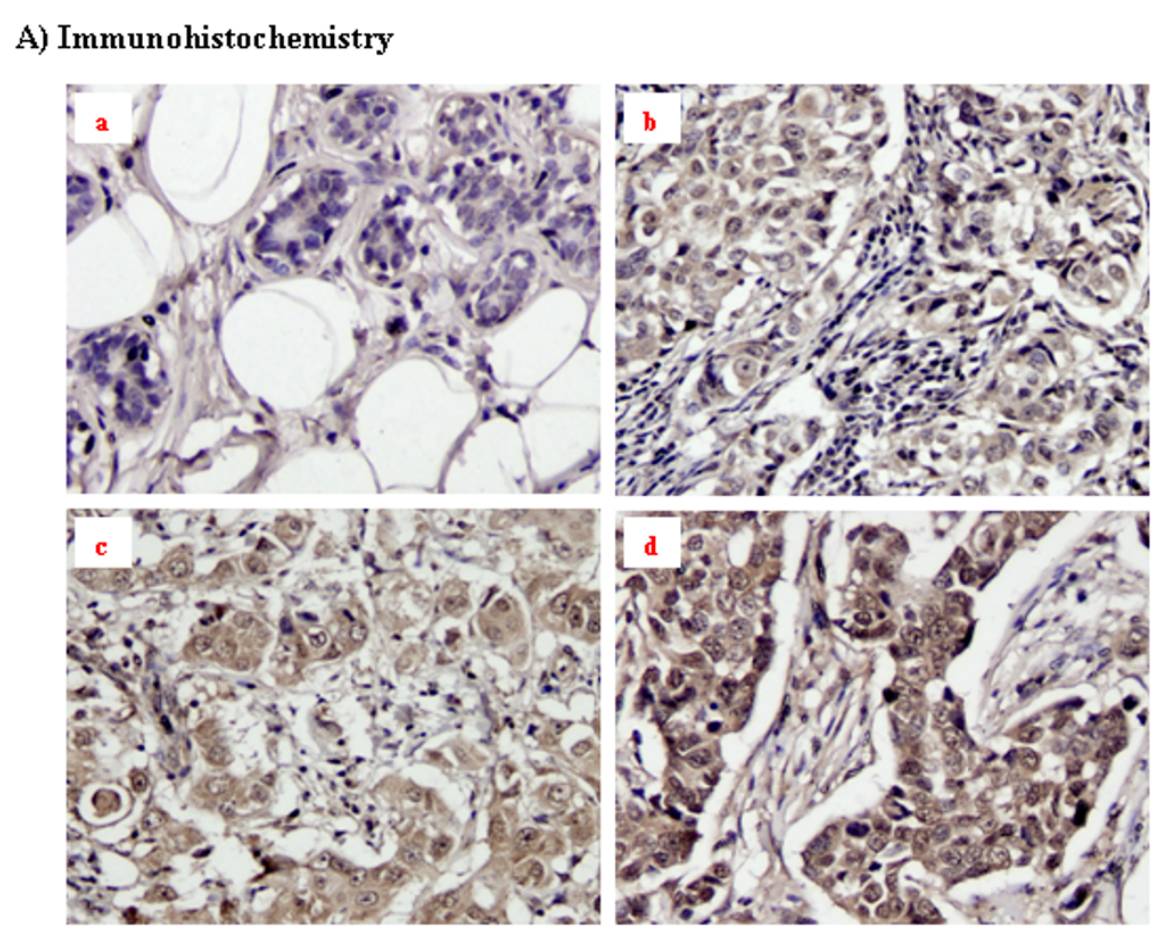

\section{B) Patient survival}

i) Overall survival

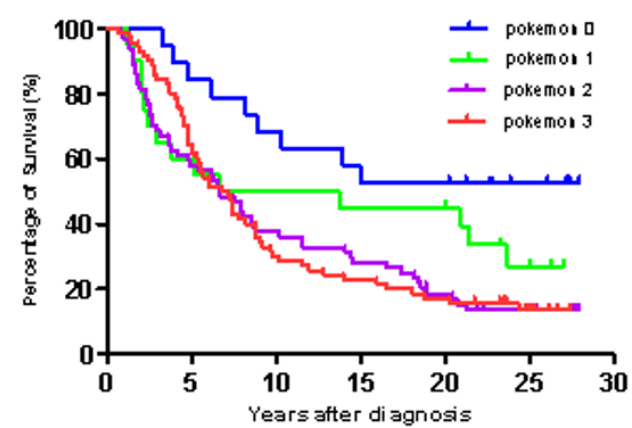

ii) Dis ease-related survival

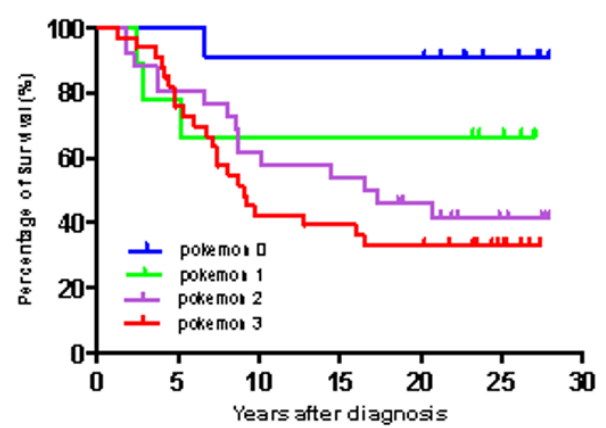

Figure 1 Pokemon expression in breast cancer tissues and its relationship with patient survival. (A) Immunohistochemistry indicating Pokemon expression in normal and malignant breast tissues. Results were scored by a researcher blinded to the samples and by a pathologist. The images show Pokemon expression in (a) normal breast lobules and in breast cancers scored as (b) 1, (c) 2 and (d) 3, respectively. (B) KaplanMeier plots of (i) overall survival $(n=175, P=0.01)$ and (ii) disease-related survival $(n=79, P=0.0134)$. Data are from the Yale Tissue Microarray (YTMA)-23 microarray containing 175 breast cancer cases with clinical data and more than 30 years of follow-up. In disease-related survival plots, disease-free survival or patients who died as a result of breast cancer are included.

Pokemon expression with these three molecular markers was assessed using Kruskal-Wallis tests, and the results showed that Pokemon expression did not correlate with ER, PR or HER2 alone or with any combination of the three genes.

\section{Survivin is a downstream target of Pokemon}

The positive correlation of Pokemon expression with disease progression suggests that Pokemon may promote cancer development. To determine the underlying mechanisms, we attempted to identify genes regulated by Pokemon in MCF-7 breast cancer cells. A total of six MCF-7 cell clones with stable Pokemon overexpression were isolated (Additional file 2), and three of them were subjected to cDNA microarray analysis. Figure 2 shows representative data of microarray analysis, in which a total of 121 genes were found to have more than a twofold increased or decreased 
Table 1 Correlation of Pokemon expression with clinicopathological parameters ${ }^{\mathrm{a}}$

\begin{tabular}{|c|c|c|c|c|c|}
\hline \multirow[b]{2}{*}{ Variables } & \multicolumn{4}{|c|}{ Pokemon $(n=182)$} & \multirow[b]{2}{*}{$P$ value } \\
\hline & 3 & 2 & 1 & 0 & \\
\hline Subtotal, $n(\%)$ & $72(39.6)$ & 69 (37.9) & $17(9.3)$ & $24(13.2)$ & \\
\hline Age, yr (\%) & & & & & 0.2451 \\
\hline$>50$ & $58(40.8)$ & $55(38.7)$ & $13(9.2)$ & $16(11.3)$ & \\
\hline$\leq 50$ & $13(33.3)$ & $14(35.9)$ & $4(10.3)$ & $8(20.5)$ & \\
\hline Tumor types, $n(\%)$ & & & & & 0.8733 \\
\hline Colloid & $3(37.5)$ & $3(37.5)$ & $1(12.5)$ & $1(12.5)$ & \\
\hline Ductal & $35(47.9)$ & 26 (35.6) & $5(6.8)$ & $7(9.6)$ & \\
\hline Lobular & $14(53.8)$ & $8(30.8)$ & $3(11.5)$ & $1(3.8)$ & \\
\hline Tumor size, $\mathrm{cm}^{3}(\%)$ & & & & & 0.0148 \\
\hline$>2$ & $47(42.7)$ & $46(41.8)$ & $9(8.2)$ & $8(7.3)$ & \\
\hline$\leq 2$ & $23(33.8)$ & $22(32.3)$ & $8(11.8)$ & $15(22.1)$ & \\
\hline Node metastasis, $n(\%)$ & & & & & 0.0014 \\
\hline Positive & $49(44.1)$ & $38(34.2)$ & $8(7.2)$ & $16(14.4)$ & \\
\hline Negative & $22(31.9)$ & $30(43.5)$ & $9(13.0)$ & $8(11.6)$ & \\
\hline Nuclear grade, $n(\%)$ & & & & & 0.057 \\
\hline 1 & $5(23.8)$ & $9(42.6)$ & $2(9.5)$ & $5(23.8)$ & \\
\hline 2 & $40(40.4)$ & $38(38.4)$ & $12(12.1)$ & $9(9.1)$ & \\
\hline 3 & $25(45.5)$ & $20(38.4)$ & $3(12.1)$ & $7(9.1)$ & \\
\hline$E R, n(\%)$ & & & & & 0.429 \\
\hline Positive & 38 (37.6) & 39 (38.6) & $11(10.9)$ & 13 (12.9) & \\
\hline Negative & $34(42.0)$ & $30(37.0)$ & $6(7.4)$ & 11 (13.6) & \\
\hline $\mathrm{PR}, n(\%)$ & & & & & 0.3444 \\
\hline Positive & $41(40.2)$ & 34 (33.3) & $14(13.7)$ & 13 (12.8) & \\
\hline Negative & 31 (38.8) & 35 (43.8) & $3(3.7)$ & $11(14.7)$ & \\
\hline$H E R 2, n(\%)$ & & & & & 0.2309 \\
\hline Positive & 31 (38.7) & $28(35.0)$ & $7(8.8)$ & $14(17.5)$ & \\
\hline Negative & $41(38.3)$ & $41(38.3)$ & $11(10.3)$ & $14(13.1)$ & \\
\hline
\end{tabular}

${ }^{\mathrm{a}}$ Data are from the Yale Tissue Microarray-23, in which 182 breast cancer cases were histologically interpretable and analyzed for the correlation of Pokemon expression with clinicopathological parameters. ER, estrogen receptor; PR, progesterone receptor; HER2, human epidermal growth factor receptor 2.

expression in Pokemon-overexpressing cells compared to the vector control. On the basis of the Kyoto Encyclopedia of Genes and Genomes and the Gene Ontology databases, these genes are classified into seven signaling and/or metabolic pathways (Figure 2C). Notably, these Pokemon target genes are mainly involved in apoptosis, cell cycle, differentiation and biosynthesis, suggesting the importance of Pokemon in cell growth, proliferation and carcinogenesis.

Interestingly, BIRC5 (survivin), a negative prognostic factor for breast cancer [38], was found to be one of the downstream targets of Pokemon. Therefore, transfection experiments were performed to determine the role of Pokemon in inducing the expression of survivin. MCF-7 cells were transfected with Pokemon expression vector to increase the level of Pokemon, while MDA-MD-231 cells were transfected with Pokemon siRNA to knock down its expression. As shown in Figure 2D(I), three different siRNA targeting 426 to $444 \mathrm{bp}, 476$ to $494 \mathrm{bp}$ and 624 to 642 bp of Pokemon mRNA successfully knocked down its expression and in turn led to a decrease of survivin, proving the cDNA microarray data. A time-course study showed that significant silencing of Pokemon by siRNA was observed at 48 hours after transfection. Interestingly, Pokemon silencing in MDA-MD-231 led to upregulation of p14ARF, but had no effect on Bcl-2 expression. In addition, transient expression of Pokemon in MCF-7 cells induced survivin upregulation in a parallel manner to Pokemon levels (Figure 2D(II)), supporting the cDNA microarray data from stable clones. Taken together, these results suggest that Pokemon indeed induces survivin expression.

\section{Survivin and Pokemon expression is highly correlated in} human breast cancer tissues

To confirm that the induction of survivin by Pokemon indeed occurs in breast cancer, adjacent tissue microarrays containing 50 breast cancer tissue samples and matching adjacent normal breast tissue samples were subjected to immunohistological analysis of Pokemon and survivin expression. As shown in Figure 3, the levels 
B) Scatter plots of Pokemon target genes

A) Pokemon expression
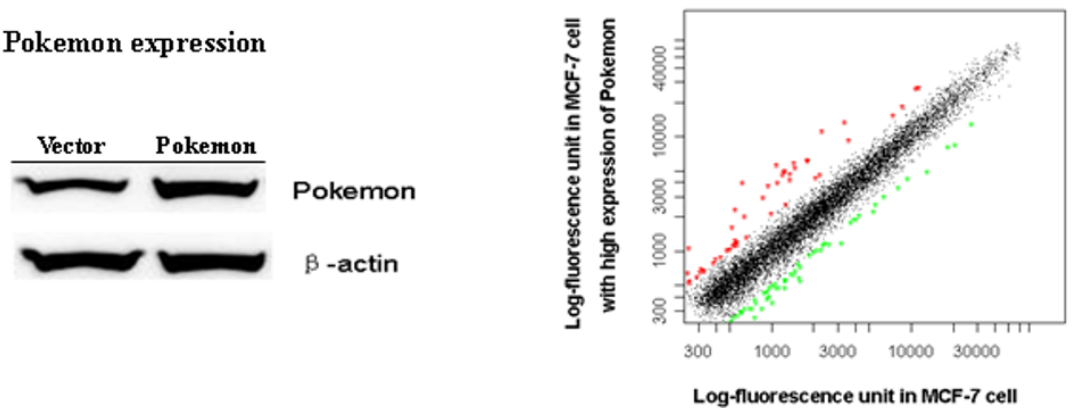

C) Functional classification of Pokemon target genes

\begin{tabular}{|c|c|c|c|c|c|c|}
\hline Apoptosis & Cell cucle & Cell growth & Transcrintion & Signal & Biosynthesis & $\begin{array}{c}\text { Transport } \\
\text { and ion }\end{array}$ \\
\hline & & Diffrentiation & regulation & Transduction & Metabolism & channel \\
\hline SULF1 & DUSP1 & SLC2A1 & CARS & $\mathrm{STC2}$ & MGC22265 & $\mathrm{KCNJ4}$ \\
\hline BIRC5 & JUN & DDIT3 & RREB 1 & WNT6 & RBKS & PKD2 \\
\hline TRIB 3 & CKS2 & NGFR & DUSP1 & PLD2 & FUT1 & COLAA 6 \\
\hline TNFRSF12A & $\mathrm{CDC} 14 \mathrm{~B}$ & TRIB3 & WARS & SULF1 & RREB 1 & $\mathrm{VMD} 2$ \\
\hline NGFR & & Cs & CARS & EFNA3 & RHOB & \\
\hline $\mathrm{RHOB}$ & & BCAT1 & DDIT3 & cxxcs & MAWBP & \\
\hline BCLAF1 & & $\mathrm{PCK} 2$ & TRIB 3 & CRLF1 & PCK2 & \\
\hline P8 & & PAX1 & SR 140 & STC2 & FUT1 & \\
\hline BCLAF1 & & DDrT3 & & & SAT & \\
\hline MYO1A & & ZMPSTE24 & & & CANnM2 & \\
\hline \multirow[t]{2}{*}{ PLCXD 1} & & TRIB3 & & & DUSP1 & \\
\hline & & & & & PLD2 & \\
\hline
\end{tabular}

D) Survivin expression affected by Pokemon

I

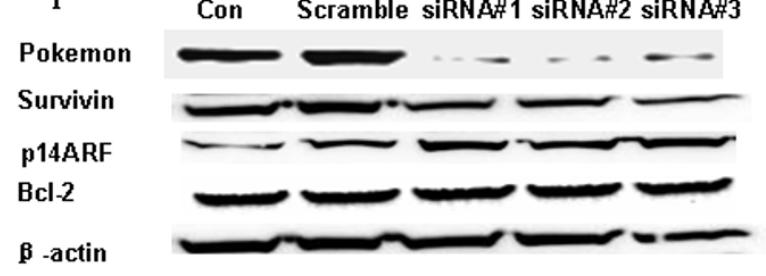

II

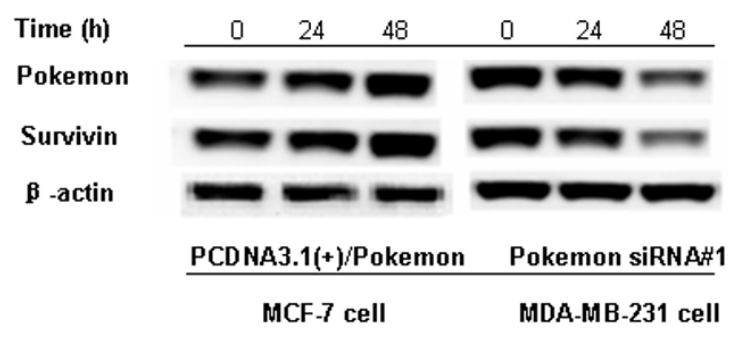

Figure 2 Target genes of Pokemon in MCF-7 cells. CDNA microarray analysis was performed as described in Materials and methods. Data from three independent replicates were combined, and any spot with at least a 2.0-fold increase or decrease compared to vector control was considered a significant change. Signaling pathways were classified by using Molecule Annotation System (MAS) 2.0 software (CapitalBio, Beijing, China ). (A) Ectopic expression of Pokemon in MCF-7 breast cancer cells detected by Western blot analysis. (B) Scatterplots showing differential expression profile of Pokemon target genes in MCF-7 cells. (C) Pathway classification of Pokemon target genes in MCF-7 cells. (D) Survivin expression regulated by Pokemon. MDA-MB-231 cells treated with siRNA for 48 hours were harvested for Western blot analysis with the indicated antibodies (I). Cells transiently transfected with either Pokemon expression vector (MCF-7 cells) or siRNA (MDA-MB-231 cells) were used for time-dependent expression by Western blot analysis as described in Materials and methods (II).

of survivin and Pokemon expression were found to be highly correlated $(r=0.6799, P<0.0001)$. In normal breast tissues, the expression levels of both Pokemon and survivin were low (data not shown).

Pokemon regulates survivin expression via DNA sequencespecific binding to its promoter

We further explored the mechanism by which Pokemon regulates the expression of survivin. The promoter region of survivin, containing 2,080 bp upstream of the transcription start site, was cloned and used to drive the expression of luciferase reporter in MCF-7 and MDAMB-231 breast cancer cells. Progressive deletions of the 5 ' end of the survivin promoter revealed that the -441 bp fragment possesses full promoter activity (Figure 4A). Promoter motif analyses recognized two GT boxes (GGGTG), located at -231 to $-227 \mathrm{bp}$ and -95 to $-91 \mathrm{bp}$, which are potential binding sites of Pokemon. Therefore, 


\section{A) Immunohistochemistry}

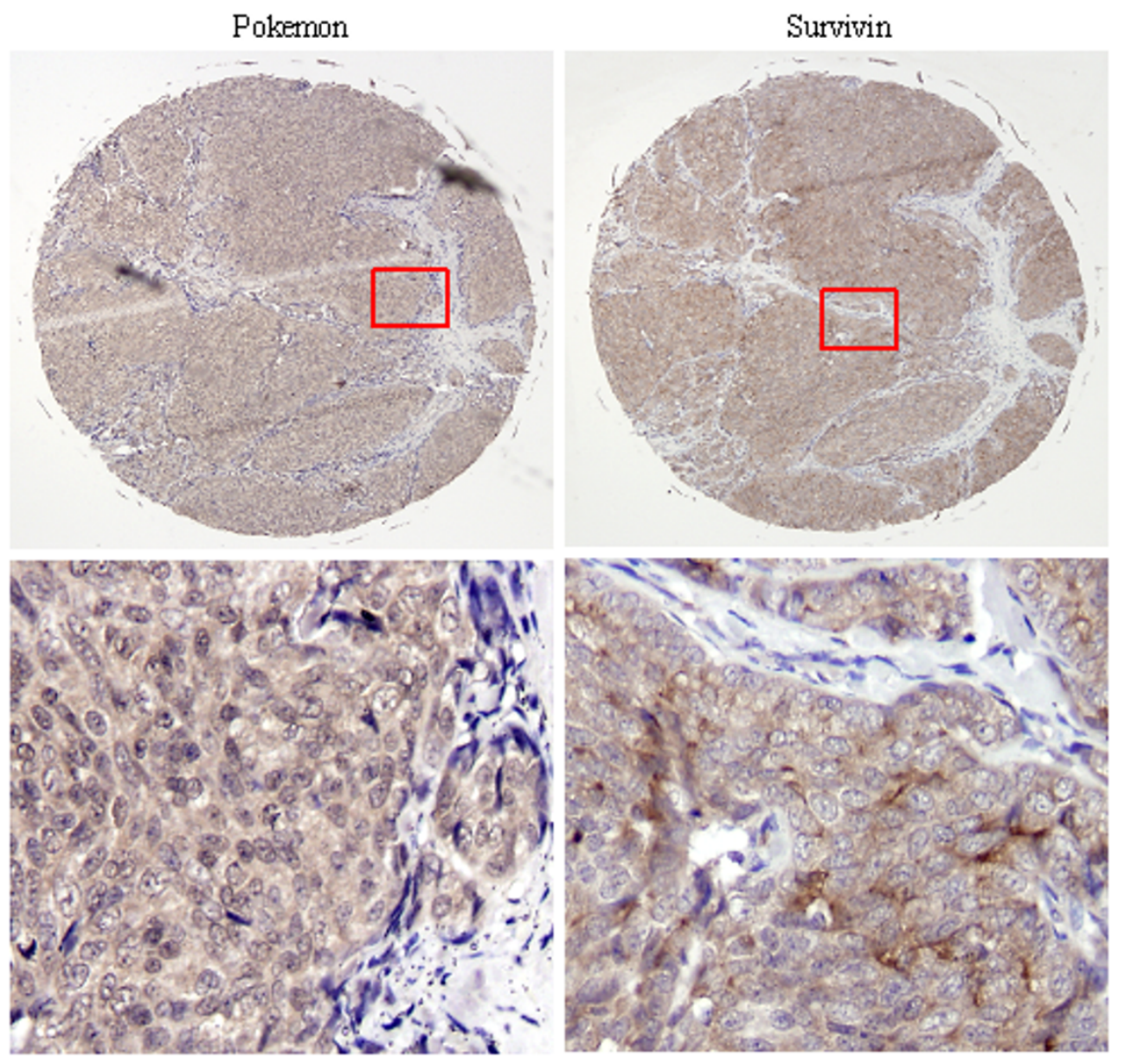

\section{B) Correlation of Pokemon and survivin expression}

\begin{tabular}{|c|c|c|c|c|c|c|c|}
\hline & \multirow{2}{*}{$\begin{array}{c}\text { Case } \\
\text { number }\end{array}$} & \multicolumn{4}{|c|}{ Staining score $(\%)$} & \multirow{2}{*}{ p value } & \multirow{2}{*}{ Speaman $r$} \\
\hline & & 0 & 1 & 2 & 3 & & \\
\hline Pokemon & 49 & $9(18.4)$ & 6 (12.2) & 16 (32.7) & $18(36.7)$ & $<0.0001$ & 0.8799 \\
\hline Survivin & 49 & 6 (12.2) & 12 (24.5) & 14 (28.6) & $17(34.7)$ & & \\
\hline
\end{tabular}

Figure 3 Correlation of survivin and Pokemon expression in breast cancer tissue. Pokemon and survivin expression in breast tissues was examined by immunohistochemistry as described in Materials and methods. (A) Images show Pokemon and survivin expression in two adjacent sections, which are histologically similar but not the same. Red boxed regions are amplified in lower panels. (B) Summary of Pokemon and survivin expression data. Spearman's rank-correlation coefficients were used to test the relationship between Pokemon and survivin expression.

this promoter fragment was used to investigate the regulatory role of Pokemon on its activity. As shown in Figure 4B, cotransfection of PCDNA3.1(+)/Pokemon greatly increased the activity of -pluc- 441 in both MCF7 and MDA-MB-231 cells, while the delivery of Pokemon siRNA significantly reduced its basal activity, suggesting Pokemon as a positive regulator of survivin promoter. Furthermore, replacing GGGTG with AAAAA in these two GT boxes of pluc-441 (luciferase plasmid at $-441 \mathrm{bp}$ ) abrogated the promoter's responsiveness to Pokemon in both MCF-7 and MDA-MB-231 cells (Figure 4B), and interaction between Pokemon and survivin promoter was further confirmed by ChIP assay. As shown in Figure 4C, survivin promoter fragment was 
A) Schemes of wild type and mutant survivin promoters

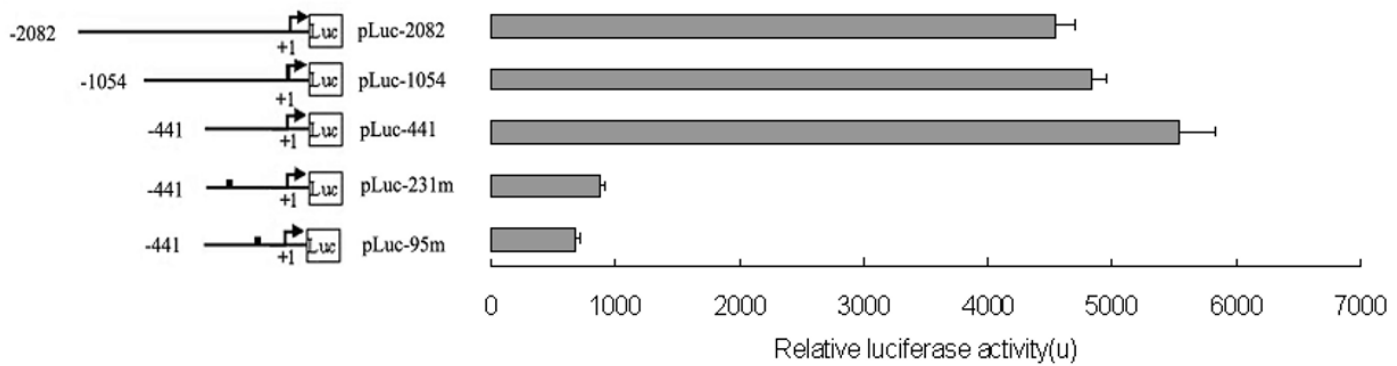

B) Effect of pokemon on survivin promoter activity
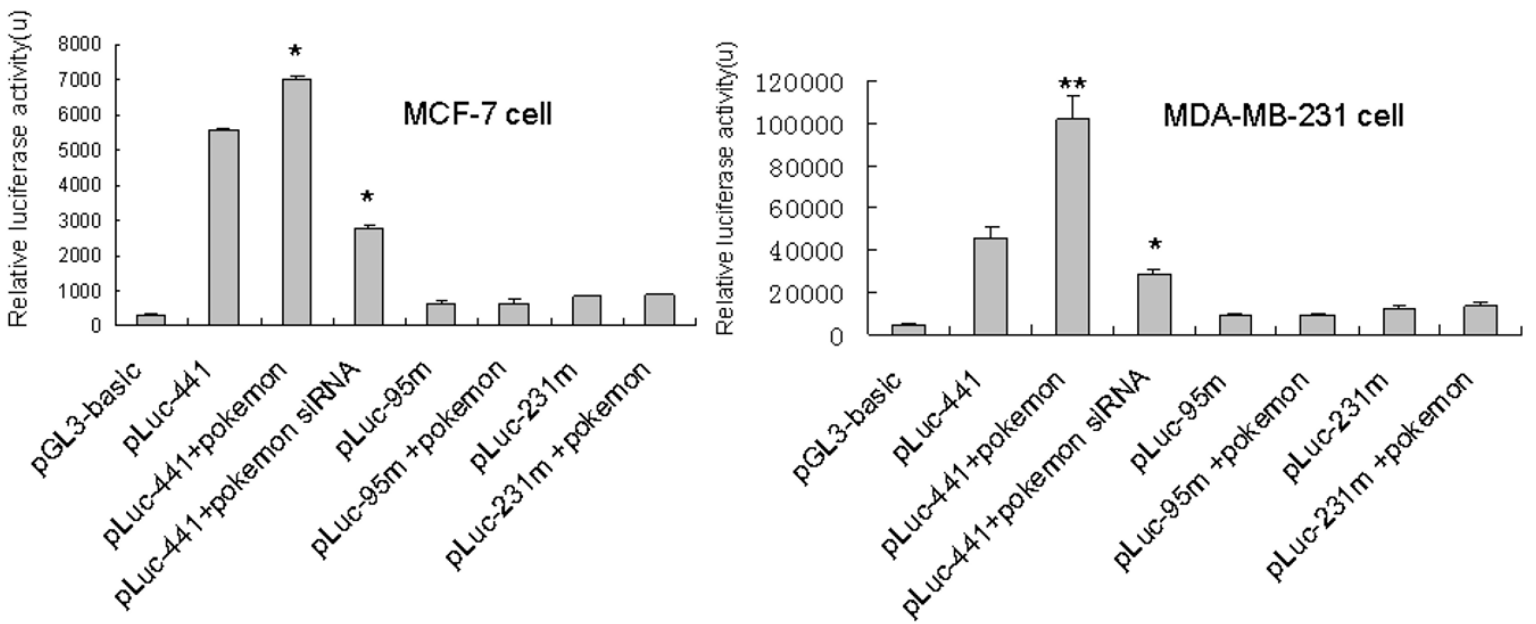

C) ChIP assay

\begin{tabular}{rrr}
\multicolumn{3}{c}{ MCF-7 cells } \\
\hline Inp ut & Pokemon IgG \\
& \\
\hline &
\end{tabular}

\begin{tabular}{cc}
\multicolumn{3}{c}{ MDA-MB-231 cels } \\
\hline Input Pokemon IgG \\
-
\end{tabular}

Figure 4 Pokemon stimulates survivin expression by direct binding to its promoter. (A) Schematic representation of survivin promoterluciferase reporter plasmids, including wild-type survivin promoter and $5^{\prime}$ progressive deletions, as well as site-directed mutants at Pokemon binding sites, pLuc-95 m (at -95 bp) and pLuc-231 m (at -231 bp). Refer to Materials and methods for the plasmid construction. Survivin promoter activity was analyzed in MCF-7 cells by luciferase assay. (B) Regulation of survivin promoter activity by Pokemon in MCF-7 and MDAMB-231 breast cancer cells. Wild-type and mutant promoter (pLuc-441) was cotransfected with Pokemon gene or Pokemon small interfering RNA siRNA\#1, and luciferase activity was measured with $\beta$-galactosidase as an internal control. Data represent the mean of three independent experiments \pm SD. Statistical significance was tested using Student's $t$-tests with ${ }^{*} P<0.05$ and ${ }^{* *} P<0.01$. (C) Chromatin immunoprecipitation assay indicating that Pokemon bound to survivin promoter in MCF-7 and MDA-MB-231 breast cancer cells. Rabbit immunoglobulin G was used as a negative control. Refer to Materials and methods for details.

amplified by polymerase chain reaction assay from chromatin precipitated by an anti-Pokemon antibody, but not by nonspecific immunoglobulin G. These data suggest that Pokemon upregulates survivin expression through direct binding to the GT boxes in its promoter.

\section{Discussion}

Pokemon is an oncogenic transcription factor. Embryonic fibroblasts (MEF) from Pokemon-null mice are resistant to cellular or viral oncogene-induced carcinogenic transformation. On the other hand, ectopic expression 
of Pokemon makes the MEF cells susceptible to oncogenic transformation. These findings suggest an important role of Pokemon in carcinogenesis [10]. In this study, we have shown that Pokemon was overexpressed in primary and recurrent breast cancer tissues and upregulated the expression of anti-apoptotic survivin, leading to disease progression and poor survival.

Using tissue microarray technology, we have shown that Pokemon was overexpressed in $86.8 \%$ of breast cancer tissue, but not in normal beast tissue, indicating its tumorspecific expression. More importantly, Pokemon expression correlated positively with tumor size and lymph node metastasis, both of which are indicators of unfavorable clinical outcome. Indeed, the level of Pokemon expression was negatively correlated with survival rate. These findings indicate that Pokemon may be a novel prognostic marker for breast cancer and a potential therapeutic target. We therefore attempted to elucidate the underlying mechanism of its tumor-promoting function.

Previous studies have shown that Pokemon functions as an oncoprotein by inhibiting the ARF/p53 pathway [10]. Using cDNA microarray analyses, we have shown that in breast cancer cells, Pokemon regulates the expression of at least 121 genes, some of which are involved in important cellular signaling/metabolic pathways. Survivin, an antiapoptotic protein and a negative prognostic indicator of breast cancer [38,39], is one of those genes whose expression was induced by Pokemon. Our study on breast cancer tissues from 50 patients (Figure 3) showed that the expression levels of survivin and Pokemon were highly correlated $(P<0.0001, r=$ $0.6799)$, suggesting that Pokemon serves as an upstream inducer of survivin in breast cancers.

Survivin is widely implicated in cell carcinogenesis, tumor progression and resistance to radiation therapy and chemotherapy [30,40]. Previous studies showed that p53 is a suppressor of survivin expression and that loss of p53 function would lead to the induction of survivin, resulting in cancer growth and resistance to chemotherapeutic agents $[28,41]$. Pokemon has been shown to repress the expression of p53 $[10,42]$. Therefore, Pokemon may induce the expression of survivin indirectly by suppressing p53. However, in this study, we have demonstrated that Pokemon can directly induce the expression of survivin by binding to the GC boxes in its promoter. This finding reveals a new signaling pathway of Pokemon-mediated oncogenesis and advances understanding of survivin regulatory mechanisms (Figure 5).

In summary, we have found that Pokemon is overexpressed specifically in breast cancer tissue, but not in normal breast tissue. Its oncogenic function may be partly due to its ability to directly induce the expression of survivin, an important cancer-promoting gene. The correlation of Pokemon expression with tumor size,

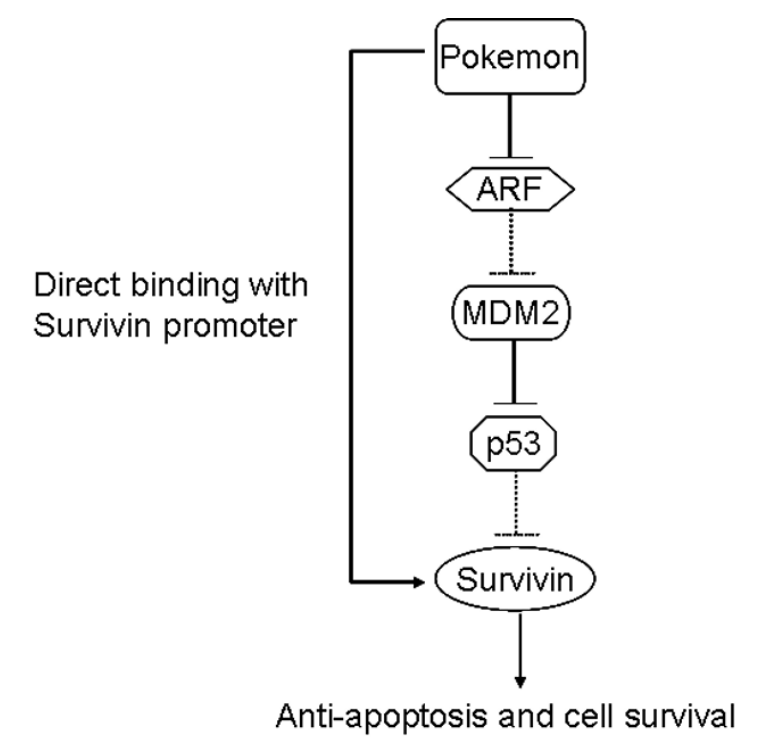

Figure 5 Hypothetic pathways by which Pokemon regulates survivin expression. p53 suppresses survivin expression and induces cell apoptosis or senescence [28,29]. Pokemon activates survivin signaling by suppressing the ARF/p53 pathway [1]. The present study shows that Pokemon also enhances survivin expression via direct binding to its promoter, promoting breast oncogenesis.

lymph node metastasis and poor patient survival suggests its potential role as a prognostic marker and therapeutic target for the treatment of this disease.

\section{Conclusions}

Pokemon was overexpressed in primary and recurrent breast cancer tissue and was correlated with tumor size, lymph node metastasis and poor patient survival, making it a potential target for the treatment of this malignancy. Pokemon might prompt breast cancer progression through upregulating the expression of survivin, an important cancer-promoting gene.

\section{Additional material}

Additional file 1: Descriptive statistics of tissue microarray. Yale Tissue Microarray (YTMA)-23 contained 246 breast cancer cases with clinical records. The descriptive statistical data are summarized below. Additional file 2: MCF-7 cell clones with stable overexpression of Pokemon. MCF-7 cells were transfected with pCDNA3.1/Pokemon or the empty vector, and the transfected cells maintained with neomycin were subjected to Western blot analysis for the detection of Pokemon expression.

\section{Abbreviations}

ChIP: chromatin immunoprecipitation assay; EGFR: epidermal growth factor receptor; FBI: factor that binds to inducer of shot transcripts 1; HER2: human epidermal growth factor receptor 2; IAP: inhibitor of apoptosis protein; KLF5: Krüppel-like factor 5; LRF: leukemia/lymphoma-related factor; PMSF:

phenylmethanesulfonyl fluoride. 


\section{Acknowledgements}

This work was supported by a grant from National 863 Project of the Ministry of Science and Technology (China, 2007AA02Z160). The authors thank the Ministry of Science and Technology of China (2009ZX09501-004 and 2007AA02Z160) and the Chinese National Natural Science Foundation (20872077 and 90813013) for financial support.

\section{Author details}

'Guangdong Provincial Key Laboratory of Chemical Biology, Graduate School at Shenzhen, Tsinghua University, Lishui Road, Shenzhen 518055, People's Republic of China. Institution of Clinical Medicine, First Affiliated Hospital of University of South China, Chuanshan Road, Hengyang 421001, People's Republic of China. ${ }^{3}$ Department of Medical Microbiology, Immunology and Cell Biology, Simmons Cancer Institute, Southern Illinois University School of Medicine, 913 North Rutledge Street, Springfield, IL 62794, USA. ${ }^{4}$ School of Medicine, Tsinghua University, Beijing 100084, People's Republic of China.

\section{Authors' contributions}

$Z X$ and JYY designed the study and drafted the manuscript. ZX, MJ, LH, LF, $T C, Y L, W J$ and XZ performed the study. CD procured the tissue microarrays and revised the paper. All authors read and approved the final manuscript.

\section{Competing interests}

The authors declare that they have no competing interests.

Received: 17 September 2010 Revised: 21 January 2011

Accepted: 10 March 2011 Published: 10 March 2011

\section{References}

1. Maeda T, Hobbs RM, Merghoub T, Guernah I, Zelent A, Cordon-Cardo C, Teruya-Feldstein J, Pandolfi PP: Role of the proto-oncogene Pokemon in cellular transformation and ARF repression. Nature 2005, 433:278-285.

2. Wei CL, Wu Q, Vega VB, Chiu KP, Ng P, Zhang T, Shahab A, Yong HC, Fu Y, Weng Z, Liu J, Zhao XD, Chew JL, Lee YL, Kuznetsov VA, Sung WK, Miller LD, Lim B, Liu ET, Yu Q, Ng HH, Ruan Y: A global map of p53 transcription-factor binding sites in the human genome. Cell 2006, 124:207-219.

3. Apostolopoulou K, Pateras IS, Evangelou K, Tsantoulis PK, Liontos M, Kittas C, Tiniakos DG, Kotsinas A, Cordon-Cardo C, Gorgoulis VG: Gene amplification is a relatively frequent event leading to ZBTB7A (Pokemon) overexpression in non-small cell lung cancer. J Pathol 2007, 213:294-302.

4. Aggarwal A, Hunter WJ, Aggarwal H, Silva ED, Davey MS, Murphy RF, Agrawal DK: Expression of leukemia/lymphoma-related factor (LRF/ POKEMON) in human breast carcinoma and other cancers. Exp Mol Pathol 2010, 89:140-148.

5. Laudes M, Bilkovski R, Oberhauser F, Droste A, Gomolka M, Leeser U, Udelhoven M, Krone W: Transcription factor FBI-1 acts as a dual regulator in adipogenesis by coordinated regulation of cyclin-A and E2F-4. J Mol Med 2008, 86:597-608.

6. Pendergrast PS, Wang C, Hernandez N, Huang S: FBI-1 can stimulate HIV1 Tat activity and is targeted to a novel subnuclear domain that includes the Tat-P-TEFb-containing nuclear speckles. Mol Biol Cell 2002, 13:915-929.

7. Kukita A, Kukita T, Ouchida M, Maeda H, Yatsuki H, Kohashi O: Osteoclastderived zinc finger (OCZF) protein with POZ domain, a possible transcriptional repressor, is involved in osteoclastogenesis. Blood 1999, 94:1987-1997.

8. Choi WI, Jeon BN, Park H, Yoo JY, Kim YS, Koh DI, Kim MH, Kim YR, Lee CE, Kim KS, Osborne TF, Hur MW: Proto-oncogene FBI-1 (Pokemon) and SREBP-1 synergistically activate transcription of fatty-acid synthase gene (FASN). J Biol Chem 2008, 283:29341-29354.

9. Maeda T, Merghoub T, Hobbs RM, Dong L, Maeda M, Zakrzewski J, van den Brink MR, Zelent A, Shigematsu H, Akashi K, Teruya-Feldstein J, Cattoretti G, Pandolfi PP: Regulation of B versus T lymphoid lineage fate decision by the proto-oncogene LRF. Science 2007, 316:860-866.

10. Maeda T, Hobbs RM, Pandolfi PP: The transcription factor Pokemon: a new key player in cancer pathogenesis. Cancer Res 2005, 65:8575-8578.

11. Lee DK, Suh D, Edenberg HJ, Hur MW: POZ domain transcription factor, FBI-1, represses transcription of $A D H 5 / F D H$ by interacting with the zinc finger and interfering with DNA binding activity of Sp1. J Biol Chem 2002, 277:26761-26768
12. Lee DK, Kang JE, Park HJ, Kim MH, Yim TH, Kim JM, Heo MK, Kim KY, Kwon $\mathrm{HJ}$, Hur MW: FBI-1 enhances transcription of the nuclear factor-KB (NF-kB)-responsive E-selectin gene by nuclear localization of the p65 subunit of NF-kB. J Biol Chem 2005, 280:27783-27791.

13. Jeon BN, Yoo JY, Choi Wl, Lee CE, Yoon HG, Hur MW: Proto-oncogene FBI1 (Pokemon/ZBTB7A) represses transcription of the tumor suppressor $R b$ gene via binding competition with $\mathrm{Sp} 1$ and recruitment of COrepressors. J Biol Chem 2008, 283:33199-33210.

14. Widom RL, Lee JY, Joseph C, Gordon-Froome I, Korn JH: The hcKrox gene family regulates multiple extracellular matrix genes. Matrix Biol 2001, 20:451-462.

15. Pessler $F$, Hernandez N: Flexible DNA binding of the BTB/POZ-domain protein FBI-1. J Biol Chem 2003, 278:29327-29335.

16. Ambrosini G, Adida C, Altieri DC: A novel anti-apoptosis gene, survivin, expressed in cancer and lymphoma. Nat Med 1997, 3:917-921.

17. Rödel F, Hoffmann J, Distel L, Herrmann M, Noisternig T, Papadopoulos T, Sauer R, Rödel C: Survivin as a radioresistance factor, and prognostic and therapeutic target for radiotherapy in rectal cancer. Cancer Res 2005, 65:4881-4887.

18. Li F: Survivin study: what is the next wave? J Cell Physiol 2003, 197:8-29.

19. Grabowski $P$, Kühnel T, Mühr-Wilkenshoff F, Heine B, Stein $H$, Höpfner M, Germer $C T$, Scherübl H: Prognostic value of nuclear survivin expression in oesophageal squamous cell carcinoma. Br J Cancer 2003, 88:115-119.

20. Adida C, Haioun C, Gaulard P, Lepage E, Morel P, Briere J, Dombret H, Reyes F, Diebold J, Gisselbrecht C, Salles G, Altieri DC, Molina TJ: Prognostic significance of survivin expression in diffuse large B-cell lymphomas. Blood 2000, 96:1921-1925.

21. Kennedy SM, O'Driscoll L, Purcell R, Fitz-Simons N, McDermott EW, Hill AD, O'Higgins NJ, Parkinson M, Linehan R, Clynes M: Prognostic importance of survivin in breast cancer. Br J Cancer 2003, 88:1077-1083.

22. Monzó M, Rosell R, Felip E, Astudillo J, Sánchez JJ, Maestre J, Martín C, Font A, Barnadas A, Abad A: A novel anti-apoptosis gene: Re-expression of survivin messenger RNA as a prognosis marker in non-small-cell lung cancers. J Clin Oncol 1999, 17:2100-2104.

23. Kawasaki H, Altieri DC, Lu CD, Toyoda M, Tenjo T, Tanigawa N: Inhibition of apoptosis by survivin predicts shorter survival rates in colorectal cancer. Cancer Res 1998, 58:5071-5074.

24. Islam A, Kageyama H, Takada N, Kawamoto T, Takayasu H, Isogai E, Ohira M, Hashizume K, Kobayashi H, Kaneko Y, Nakagawara A: High expression of Survivin, mapped to $17 q 25$, is significantly associated with poor prognostic factors and promotes cell survival in human neuroblastoma. Oncogene 2000, 19:617-623.

25. Kajiwara Y, Yamasaki F, Hama S, Yahara K, Yoshioka H, Sugiyama K, Arita K Kurisu K: Expression of survivin in astrocytic tumors: correlation with malignant grade and prognosis. Cancer 2003, 97:1077-1083.

26. Asanuma H, Torigoe T, Kamiguchi K, Hirohashi Y, Ohmura T, Hirata K, Sato M, Sato N: Survivin expression is regulated by coexpression of human epidermal growth factor receptor 2 and epidermal growth factor receptor via phosphatidylinositol 3-kinase/AKT signaling pathway in breast cancer cells. Cancer Res 2005, 65:11018-11025.

27. Hoffman WH, Biade S, Zilfou JT, Chen J, Murphy M: Transcriptional repression of the anti-apoptotic survivin gene by wild type p53. J Biol Chem 2002, 277:3247-3257.

28. Mirza A, McGuirk M, Hockenberry TN, Wu Q, Ashar H, Black S, Wen SF, Wang L, Kirschmeier P, Bishop WR, Nielsen LL, Pickett CB, Liu S: Human survivin is negatively regulated by wild-type $\mathrm{p} 53$ and participates in p53-dependent apoptotic pathway. Oncogene 2002, 21:2613-2622.

29. Zhou M, Gu L, Li F, Zhu Y, Woods WG, Findley HW: DNA damage induces a novel p53-survivin signaling pathway regulating cell cycle and apoptosis in acute lymphoblastic leukemia cells. J Pharmacol Exp Ther 2002, 303:124-131.

30. Li F, Altieri DC: Transcriptional analysis of human survivin gene expression. Biochem J 1999, 344:305-311.

31. Siddiqui SF, Pawelek J, Handerson T, Lin CY, Dickson RB, Rimm DL, Camp RL: Coexpression of $\beta 1,6-N$-acetylglucosaminyltransferase $V$ glycoprotein substrates defines aggressive breast cancers with poor outcome. Cancer Epidemiol Biomarkers Prev 2005, 14:2517-2523.

32. Giltnane JM, Moeder CB, Camp RL, Rimm DL: Quantitative multiplexed analysis of ErbB family coexpression for primary breast cancer prognosis in a large retrospective cohort. Cancer 2009, 115:2400-2409. 
33. Yan R, Zu X, Ma J, Liu Z, Adeyanju M, Cao D: Aldo-keto reductase family 1 B10 gene silencing results in growth inhibition of colorectal cancer cells: Implication for cancer intervention. Int J Cancer 2007, 121:2301-2306.

34. Zu X, Yan R, Robbins S, Krishack PA, Liao DF, Cao D: Reduced 293T cell susceptibility to acrolein due to aldose reductase-like-1 protein expression. Toxicol Sci 2007, 97:562-568.

35. Zu X, Yu L, Sun Q, Liu F, Wang J, Xie Z, Wang Y, Xu W, Jiang Y: SP1 enhances Zbtb7A gene expression via direct binding to $G C$ box in HePG2 cells. BMC Res Notes 2009, 2:175.

36. Liu Z, Zhong L, Krishack PA, Robbins S, Cao JX, Zhao Y, Chung S, Cao D: Structure and promoter characterization of aldo-keto reductase family 1 B10 gene. Gene 2009, 437:39-44.

37. Chung SW, Chen YH, Yet SF, Layne MD, Perrella MA: Endotoxin-induced down-regulation of Elk-3 facilitates heme oxygenase-1 induction in macrophages. J Immunol 2006, 176:2414-2420.

38. Paik S, Shak S, Tang G, Kim C, Baker J, Cronin M, Baehner FL, Walker MG Watson D, Park T, Hiller W, Fisher ER, Wickerham DL, Bryant J, Wolmark N: A multigene assay to predict recurrence of tamoxifen-treated, nodenegative breast cancer. N Engl J Med 2004, 351:2817-2826.

39. Lu J, Tan M, Huang WC, Li P, Guo H, Tseng LM, Su XH, Yang WT, Treekitkarnmongkol W, Andreeff M, Symmans F, Yu D: Mitotic deregulation by survivin in ErbB2-overexpressing breast cancer cells contributes to Taxol resistance. Clin Cancer Res 2009, 15:1326-1334.

40. Spaulding B, Pan D, Ghadersohi A, Nielsen G, Jensen S, Gellert F, Ling X, Zhang M, Black A, Li F: Characterization of the 12 C4 survivin monoclonal antibody and insight into the expression of survivin in human adult tissues. Histopathology 2006, 49:622-633.

41. Zhu N, Gu L, Findley HW, Chen C, Dong JT, Yang L, Zhou M: KLF5 interacts with p53 in regulating survivin expression in acute lymphoblastic leukemia. J Biol Chem 2006, 281:14711-14718.

42. Agrawal A, Yang J, Murphy RF, Agrawal DK: Regulation of the p14ARFMdm2-p53 pathway: an overview in breast cancer. Exp Mol Pathol 2006, 81:115-122.

doi:10.1186/bcr2843

Cite this article as: Zu et al:: Pro-oncogene Pokemon promotes breast cancer progression by upregulating survivin expression. Breast Cancer Research 2011 13:R26.

\section{Submit your next manuscript to BioMed Central and take full advantage of:}

- Convenient online submission

- Thorough peer review

- No space constraints or color figure charges

- Immediate publication on acceptance

- Inclusion in PubMed, CAS, Scopus and Google Scholar

- Research which is freely available for redistribution

Submit your manuscript at www.biomedcentral.com/submit 